\title{
Caracterização mineralógica de pegmatitos litiníferos da região de Araçuaí - MG
}

\section{Mineralogical characterization of lithiniferous pegmatite from the Araçuaí region of Minas Gerais}

\author{
Eliotério, A.A. ${ }^{1}$; Gonçalves, F.M. ${ }^{2}$; Paulino, G.M. ${ }^{3 *}$; Alexandrino, J.S. ${ }^{4}$ \\ 1,2,3,4 Universidade do Estado de Minas Gerais, João Monlevade, MG, Brasil. \\ Gleicia.paulino@uemg.br
}

\begin{abstract}
RESUMO
A atual relevância do uso de lítio na fabricação de veículos elétricos e em equipamentos portáteis tem gerado uma crescente demanda por esse metal, despertando o interesse mundial por sua extração e seu beneficiamento. Portanto, o lítio tornou-se rapidamente um metal estratégico e sua exploração precisa ser mais investigada visando maximizar sua recuperação. Nesse sentido, um pegmatito litinífero da região nordeste de Minas Gerais foi estudado, adequando sua granulometria através de processos de cominuição para uma análise mineralógica por difração de raios X. A amostra apresentou em sua composição cerca de $42,6 \%$ de espodumênio, principal mineral-minério de lítio, mostrando o potencial das rochas dessa região para ulterior aproveitamento.
\end{abstract}

Palavras-chave: Caracterização Mineralógica, Espodumênio, Lítio.

\begin{abstract}
The current relevance of lithium use in the manufacture of electric vehicles and portable equipment has generated an increasing demand for this metal, arousing the worldwide interest for its extraction and beneficiation. Therefore, lithium has quickly become a strategic metal which needs to be further investigated for its maximize use. In this sense, a lithiniferous pegmatite from the northeastern region of Minas Gerais was studied, adjusting its granulometry through comminution processes for a mineralogical analysis by X-ray diffraction. The sample presented in its composition about $42.6 \%$ of spodumene, the main ore mineral for lithium, showing the potential of the rocks of this region for subsequent use.
\end{abstract}

KEYWORDS: Mineralogical characterization, Spodumene, Lithium.

\section{INTRODUÇÃ̃O}

A atual relevância do uso de lítio na fabricação de vários equipamentos como, por exemplo, baterias de carros híbridos e de dispositivos portáteis, tem gerado uma crescente demanda por minerais litiníferos, despertando interesse mundial por sua extração e beneficiamento. Dessa forma, o lítio (Li) se tornou rapidamente um metal 
estratégico, que permitirá principalmente uma mobilidade sustentável nas próximas décadas (Margarido et al., 2014).

No Brasil, as principais reservas de minerais de lítio estão situadas na região sudeste (Minas Gerais) e nordeste (Ceará e Rio Grande do Norte), geralmente proveniente de pegmatitos litiníferos, tendo o espodumênio como o minério mais importante. Os pegmatitos são rochas ígneas de granulometria grossa geradas pela cristalização de líquidos pós-magmáticos, formando corpos tabulares que podem apresentar grandes dimensões. Mineralogicamente, os pegmatitos litiníferos são compostos por quartzo, feldspato e mica, sendo que o espodumênio e os demais minerais de lítio ocorrem como um mineral acessório. Embora o lítio ocorra em diferentes minerais, somente o espodumênio, a ambligonita e a petalita são utilizados atualmente como fontes comerciais de lítio (Braga e Sampaio, 2008).

De acordo com Braga e França (2011), a produção industrial de compostos de lítio no Brasil é obtida, em sua maioria, diretamente do mineral espodumênio, um aluminossilicato $\left(\mathrm{LiAlSi}_{2} \mathrm{O}_{6}\right)$ que pode conter até $3,73 \% \mathrm{Li}\left(8,03 \% \mathrm{Li}_{2} \mathrm{O}\right)$. Para que um minério de lítio seja utilizado em algum processo, é preciso primeiro conhecer as suas propriedades mineralógicas, físicas e químicas.

O conhecimento das características principais dos minerais contidos em amostras representativas do tipo run of mine é feito sobre fragmentos de rochas ou em amostras e produtos granulares representativos. Esse procedimento auxilia o engenheiro de processo com informações que estejam relacionadas diretamente ao desenvolvimento e otimização das técnicas de beneficiamento mineral para fins metalúrgicos. É necessário que as informações obtidas nos estudos de mineralogia aplicada não se limitem apenas à identificação dos constituintes da amostra, mas que apresentem sempre avaliações quantitativas ou semiquantitativas desses constituintes, objetivando melhores recuperações dos minerais valiosos (PORPHÍRIO, BARBOSA e BERTOLINO, 2010; VALADÃO e ARAÚJO, 2012).

Uma caracterização como essa possibilita o uso potencializado desse recurso natural, gerando maior confiabilidade, aumento de produtividade e maiores ganhos econômicos desde as etapas iniciais de mineração e beneficiamento até a transformação do bem produtivo propriamente dito. Tendo como base o aumento do interesse por minerais de lítio, este trabalho tem como objetivo a caracterização mineralógica de pegmatitos litiníferos, provenientes da região nordeste do estado de $\mathrm{MG}$, a fim de 
ampliar o conhecimento sobre as propriedades desse recurso mineral. Os objetivos específicos foram: determinar a distribuição granulométrica de pegmatitos litiníferos, identificar e quantificar as fases minerais presentes no mesmo, em especial, o mineral espodumênio.

\section{MATERIAIS E MÉTODOS}

\subsection{Amostragem}

A coleta das amostras de pegmatito litinífero foi realizada na pilha de ROM da Mina de Cachoeira, pertencente à Companhia Brasileira de Lítio, localizada em Araçuaí, região nordeste de Minas Gerais, que realiza o método de mineração subterrânea para extração dos pegmatitos litiníferos, onde o minério de espudomênio é dominante.

O material amostrado (Figura 1), cerca de $15 \mathrm{~kg}$ de rochas, foi ensacado em saco plástico limpo, para evitar contaminações, e encaminhado para o Laboratório de Tratamento de Minérios da Universidade do Estado de Minas Gerais (UEMG) Unidade João Monlevade para preparo das amostras e posteriores análises.

Figura - Amostras de pegmatito litinífero coletadas

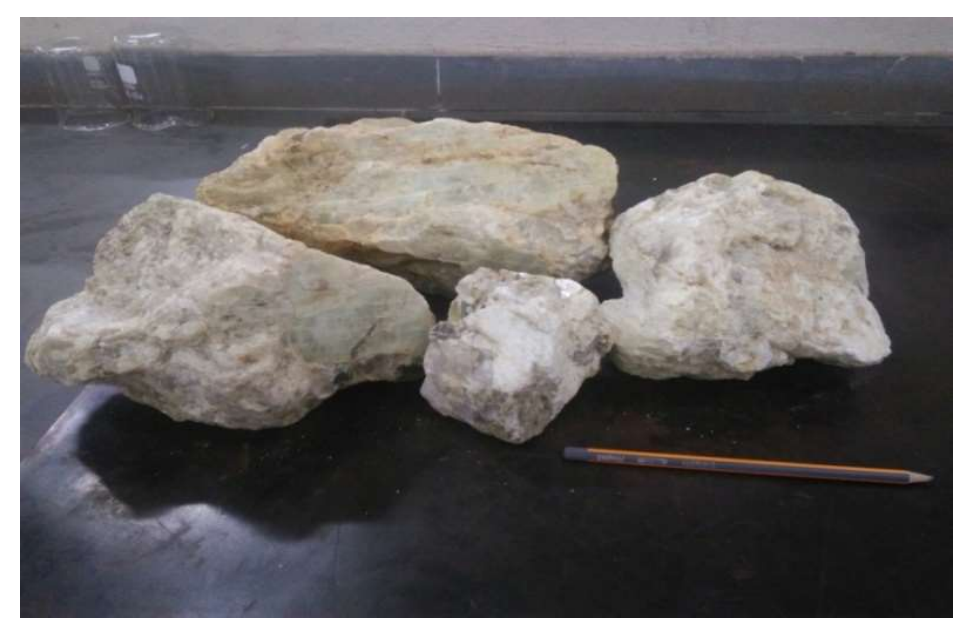

Fonte: Pesquisa documental, 2017.

\subsection{Fragmentação}


A britagem teve como finalidade a fragmentação de blocos de minérios vindos das minas, levando-os à granulometria desejada para a utilização direta ou para processos posteriores.

Primeiramente, a amostra de pegmatito litinífero foi quebrada em partes menores, com o auxílio de um martelo, para adequá-la à abertura do britador $(19,7 \mathrm{~mm})$, a qual foi medida utilizando-se um paquímetro. Posteriormente, uma alíquota de cerca de $1,133 \mathrm{~kg}$ foi levada ao britador de mandíbulas modelo BM 120080 para a britagem; como mostrado na figura 2.

Figura 2 - Amostra do minério sendo britada no britador de mandíbulas

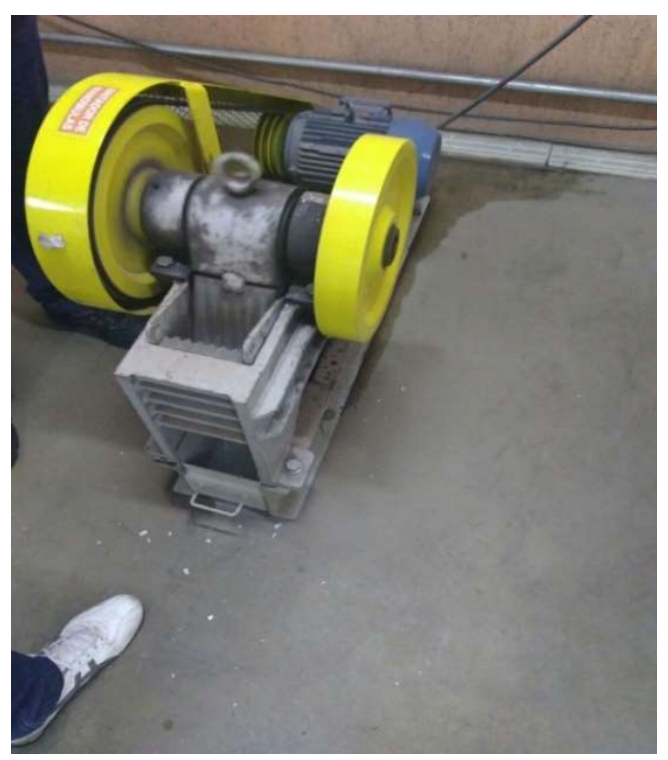

Fonte: Pesquisa documental, 2017.

\subsection{Cominuição}

A moagem é uma operação de fragmentação que visa a obtenção de um produto mais fino e dentro das especificações desejadas para serem usadas posteriormente na concentração mineral ou em processos industriais diversos.

Na cominuição optou-se pela utilização do moinho de disco modelo MD200 (Figura 3), uma vez que este é mais indicado para a moagem de granulação fina. Todo o material proveniente do britador seguiu para a moagem, porém vale ressaltar que houve uma perda de $45 \mathrm{~g}$ de material durante a britagem, portanto $1,088 \mathrm{Kg}$ foram utilizados 
nessa etapa. A amostra do minério de espudomênio passou três vezes pela etapa de moagem, visando reduzir ainda mais sua granulometria para as análises subsequentes.

Figura 3 - Amostra pegmatito litinífero sendo cominuida no Moinho de Disco modelo MD200

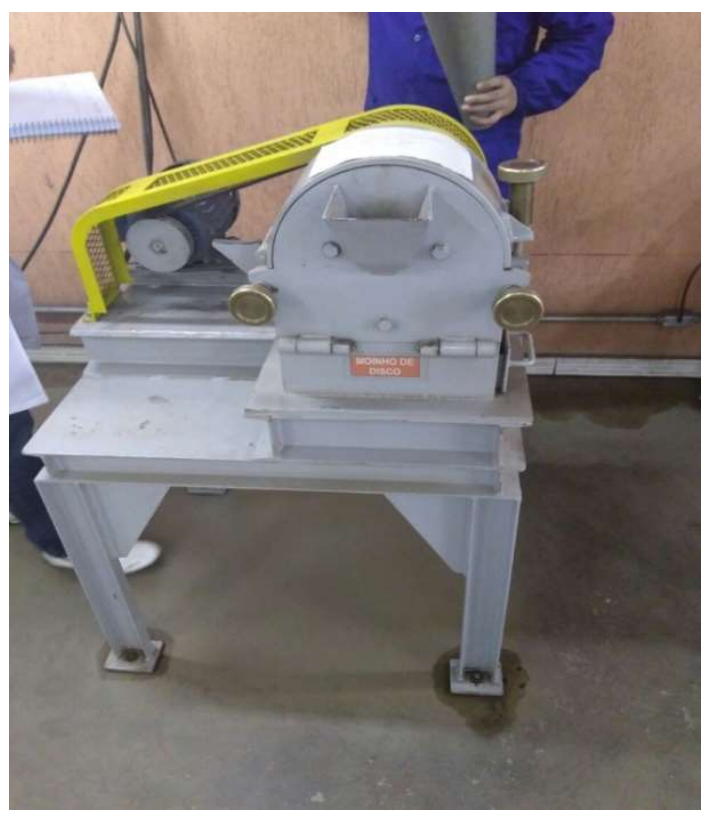

Fonte: Pesquisa documental, 2017.

\subsection{Análise granulométrica}

Os ensaios de peneiramento têm como objetivo classificar o material de acordo com o tamanho das partículas presentes na amostra, neste caso, no intuito de conhecer a distribuição granulométrica do pegmatito litinífero, que contém o mineral espodumênio. Esta análise foi realizada no Laboratório de Tratamento de Minérios da UEMG-Unidade João Monlevade.

Para dar início aos ensaios, a amostra de pegmatito litinífero advinda da etapa de moagem foi primeiramente homogeneizada e passou pelo processo de quarteamento, com auxílio da cruzeta (Figura 4), para redução da quantidade de massa, obtendo-se uma alíquota de 548,1g. Para o peneiramento a seco, foi utilizado um peneirador vibratório suspenso; utilizaram-se peneiras da série Tyler, com aberturas de $0,425 \mathrm{~mm}$ (40\#);0,250mm (60\#);0,149mm (100\#);0,105mm (140\#);0,074mm (200\#);0,053mm $(270 \#)$ e $0,045 \mathrm{~mm}(325 \#)$. A figura 5 ilustra a etapa de peneiramento. 
Figura 4 - Homogeneização e quarteamento da amostra de pegmatito litinífero

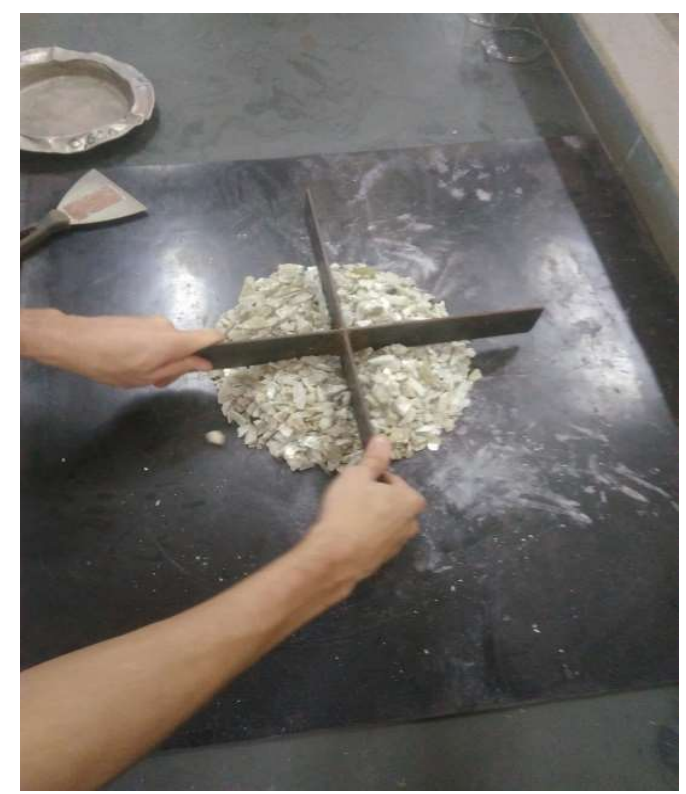

Fonte: Pesquisa documental, 2017.

Figura 5 - Peneiramento a seco da amostra de pegmatito litinífero

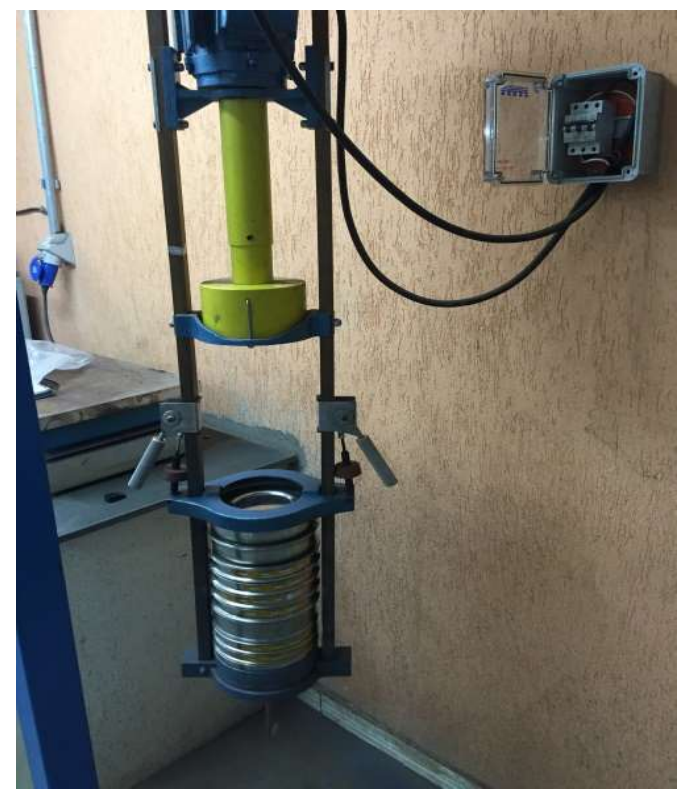

Fonte: Pesquisa documental, 2017.

\subsection{Análise mineralógica}

Uma alíquota de $370 \mathrm{~g}$ da amostra cominuída do pegmatito litinífero foi retirada e enviada ao laboratório para análise mineralógica, a qual foi realizada através da técnica de difração de raios $\mathrm{X}$. A difração de raios $\mathrm{X}$ permite a identificação de fases 
presentes em materiais policristalinos, uma vez que, quando os raios $\mathrm{X}$ interagem com uma substância cristalina, forma-se um padrão de difração que pode ser comparado com dados conhecidos da literatura (MATOS, 2016).

Para análise da amostra de pegmatitos realizada por difração de raios $\mathrm{X}$, foi utilizado o método de pó, usando radiação $\mathrm{K} \alpha$ do Cobre $(\mathrm{Cu})$ e realizada em um difratômetro Shimadzu XRD-6000. As medidas foram feitas no intervalo de 20 a $90^{\circ}$, sob corrente de $30 \mathrm{~mA}$ e tensão de $40 \mathrm{kV}$. Esta análise foi realizada em parceria com a Universidade Federal de Minas gerais (UFMG), no Laboratório do Departamento de Engenharia de Minas.

Além disso, utilizou-se o método de refinamento Rietveld e o programa estatístico numérico da série DBWS-9807 para adequação do difratograma e quantificação das fases minerais presentes na amostra. $O$ método Rietveld é uma metodologia de refinamento de estruturas cristalinas, realizada a partir da difração de raios $\mathrm{X}$ ou nêutrons, por pó, de forma que o difratograma obtido a partir da amostra se aproxime o máximo possível do difratograma teórico. Parâmetros estatísticos numéricos são utilizados para verificar a qualidade do refinamento de maneira que, após o refinamento, os valores atingidos estejam o mais próximo possível da representação da estrutura cristalina real. O método Rietveld permite realizar o refinamento da célula unitária, de estrutura cristalina, a análise quantitativa das fases e a determinação da orientação preferencial, mesmo em picos de menor intensidade, porque a velocidade de refinamento, 5 segundos por passo, é muito baixa em relação àquela utilizada na difração de raios X (RODRIGUES, 2014; YOUNG, LARSON e PAIVA-SANTOS, 1998).

\section{RESULTADOS E DISCUSSÃO}

\subsection{Etapas de cominuição e análise granulométrica}

O pegmatito litinífero que contém o minério de espodumênio apresentou bom resultado na etapa de britagem, dando origem a fragmentos menores, uniformes e adequados para a etapa seguinte. A figura 6 ilustra a amostra após a britagem. 
Figura 6 - Amostra de pegmatito litinífero após a britagem

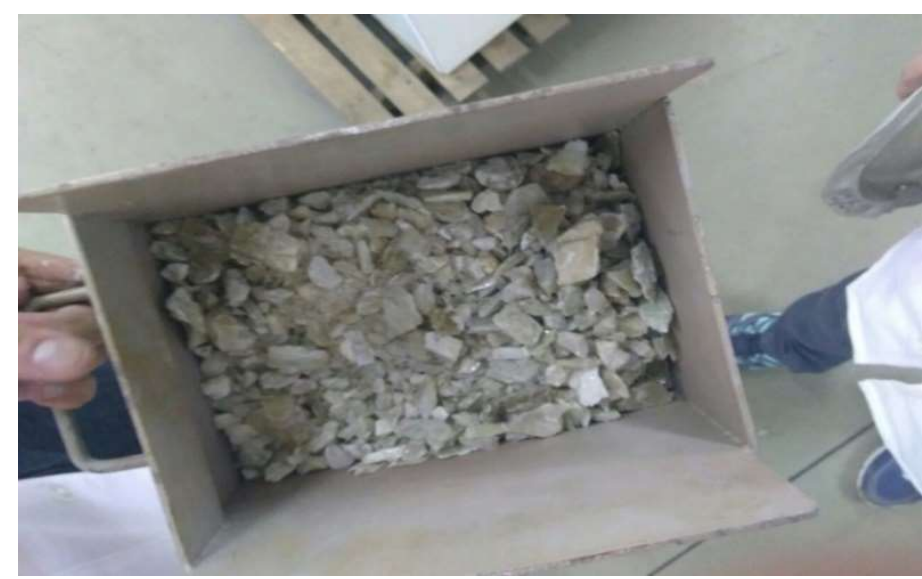

Fonte: Pesquisa documental, 2017.

$\mathrm{Na}$ etapa de cominuição, foi necessário repassar a amostra três vezes no moinho de disco para que ela atingisse um tamanho adequado para as análises subsequentes, de granulometria e mineralógicas. Isso, assim como descrito na bibliografia, se deve ao fato de os cristais de espudomênio contidos na amostra de pegmatito possuírem uma dureza relativamente alta $(6,5$ - 7,0) na escala de Mohs. Notou-se também a grande quantidade de micas transparentes (lamelas) após a primeira liberação, acarretando uma possível diminuição da eficiência na cominuição do material, sendo necessários mais dois ciclos de moagem de 15 minutos. A figura 7 ilustra a amostra após a etapa de moagem.

Figura 7 - Amostra de pegmatito litinífero após a moagem

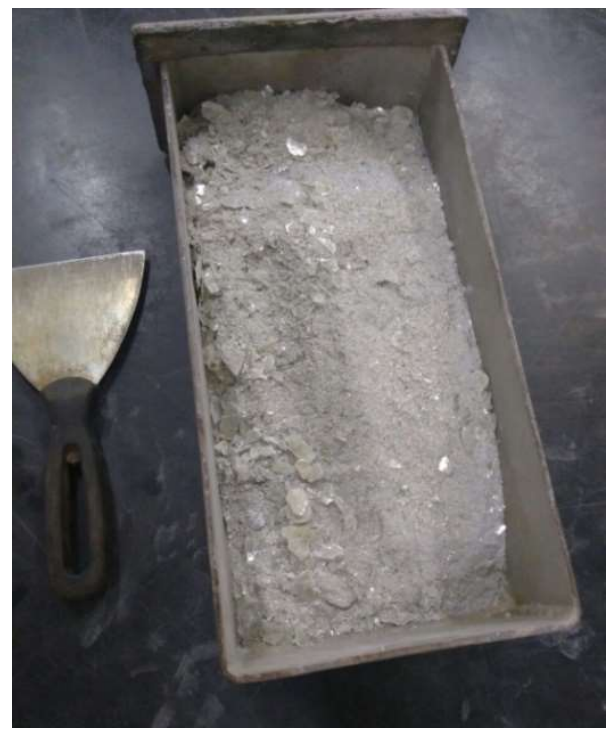

Fonte: Pesquisa documental, 2017. 
O ensaio de peneiramento se mostrou importante para conhecer as características das partículas minerais contidas na amostra de pegmatito litinífero em determinadas faixas de tamanho, dentro dos parâmetros que foram estabelecidos e usados nas etapas de britagem e moagem. Além de evidenciar que a amostra moída está dentro da faixa para ser analisada mineralogicamente pelos métodos pré-estabelecidos.

O ensaio de peneiramento a seco foi executado de acordo com a norma NBR NM 248 (BRASIL, 2003), que trata de agregados - determinação da composição granulométrica. Conforme citado na norma, o relatório do ensaio deve conter a porcentagem média retida e a porcentagem média retida acumulada em cada peneira. A tabela 1 mostra a distribuição granulométrica do pegmatito litinífero de espodumênio após a etapa de moagem.

Tabela 1 - Distribuição granulométrica da amostra de pegmatito litinífero

\begin{tabular}{|c|c|c|c|c|c|}
\hline \multicolumn{2}{|c|}{ Faixa granulométrica } & \multicolumn{2}{|c|}{ Massa inicial $=584,1 \mathrm{~g}$} & \multirow[b]{2}{*}{$\begin{array}{l}\text { \% Retido } \\
\text { acumulado }\end{array}$} & \multirow[b]{2}{*}{$\%$ passantes } \\
\hline MeshTyler & Aberturas & Peso(g) & $\%$ Retido & & \\
\hline & $(\mathrm{mm})$ & $\mathrm{t}=15 \mathrm{~min}$ & $\mathrm{t}=15 \mathrm{~min}$ & $\mathrm{t}=15 \mathrm{~min}$ & $t=15 \min$ \\
\hline 40 & 0,425 & 337,40 & 62,01 & 62,01 & 38,00 \\
\hline 60 & 0,25 & 84,60 & 15,55 & 77,56 & 22,40 \\
\hline 100 & 0,15 & 48,00 & 8,82 & 86,38 & 13,60 \\
\hline 140 & 0,106 & 22,90 & 4,21 & 90,59 & 9,40 \\
\hline 200 & 0,074 & 18,70 & 3,44 & 94,03 & 6,00 \\
\hline 270 & 0,053 & 10,80 & 1,98 & 96,01 & 4,00 \\
\hline 325 & 0,045 & 6,50 & 1,19 & 97,21 & 2,80 \\
\hline Fundo & $-0,045$ & 15,20 & 2,79 & 100,00 & $\mathbf{0 , 0 0}$ \\
\hline Total (g) & & 544,10 & & & \\
\hline Perda (g) & & $40 \mathrm{~g}$ & & & \\
\hline
\end{tabular}

Fonte: Pesquisa aplicada, 2017.

Analisando os dados apresentados na tabela 1, plotou-se o gráfico 1, em escala logarítmica no eixo das abscissas, no intuito de representar o passante acumulado em função da abertura das peneiras. Dessa forma, somente $18 \%$ da amostra foi considerada ultrafina (menor que $0,15 \mathrm{~mm}$ ) e os outros $82 \%$ é considerada como fina (entre $6,35 \mathrm{~mm}$ e $0,15 \mathrm{~mm}$ ) (NBR 248, 2003). Como o intuito do trabalho era uma caracterização mineralógica, aqui não foram considerados parâmetros de eficiência das etapas de cominuição e peneiramento para uma possível adequação ao beneficiamento mineral. 
Gráfico 1 - Passante acumulado

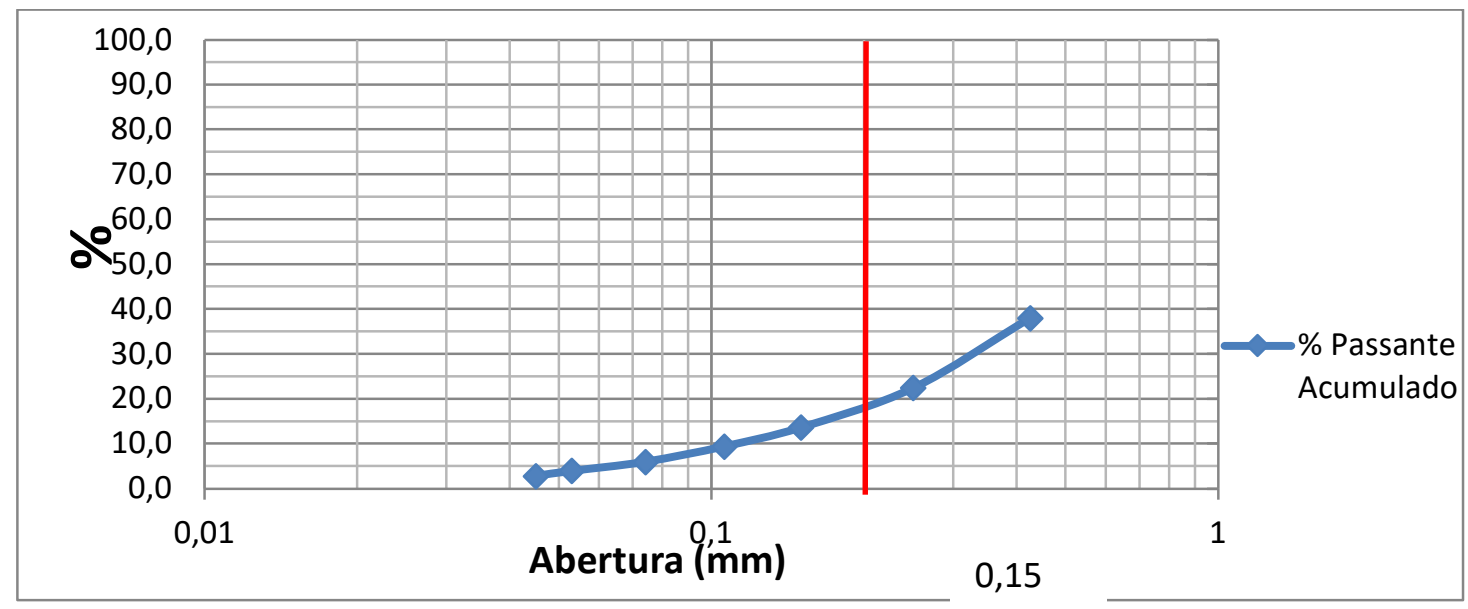

Fonte: Pesquisa aplicada, 2017.

A especificação para as análises do laboratório de DRX são granulometria abaixo de $200 \#$ e mínimo de $5 \mathrm{~g}$, portanto, somente foi considerado o material passante na malha abaixo de 0,074 mm (200\#). Assim, o minério dessas faixas (cerca de 35,2g) foi homogeneizado, e uma alíquota de $20 \mathrm{~g}$ dessa amostra foi retirada para envio ao laboratório da UFMG para a análise mineralógica.

\subsection{Análise mineralógica}

O difratograma obtido para a amostra de pegmatito litinífero é apresentado na figura 8 . 
Figura 8 - Difratograma de raios $\mathrm{X}$ da amostra de pegmatito

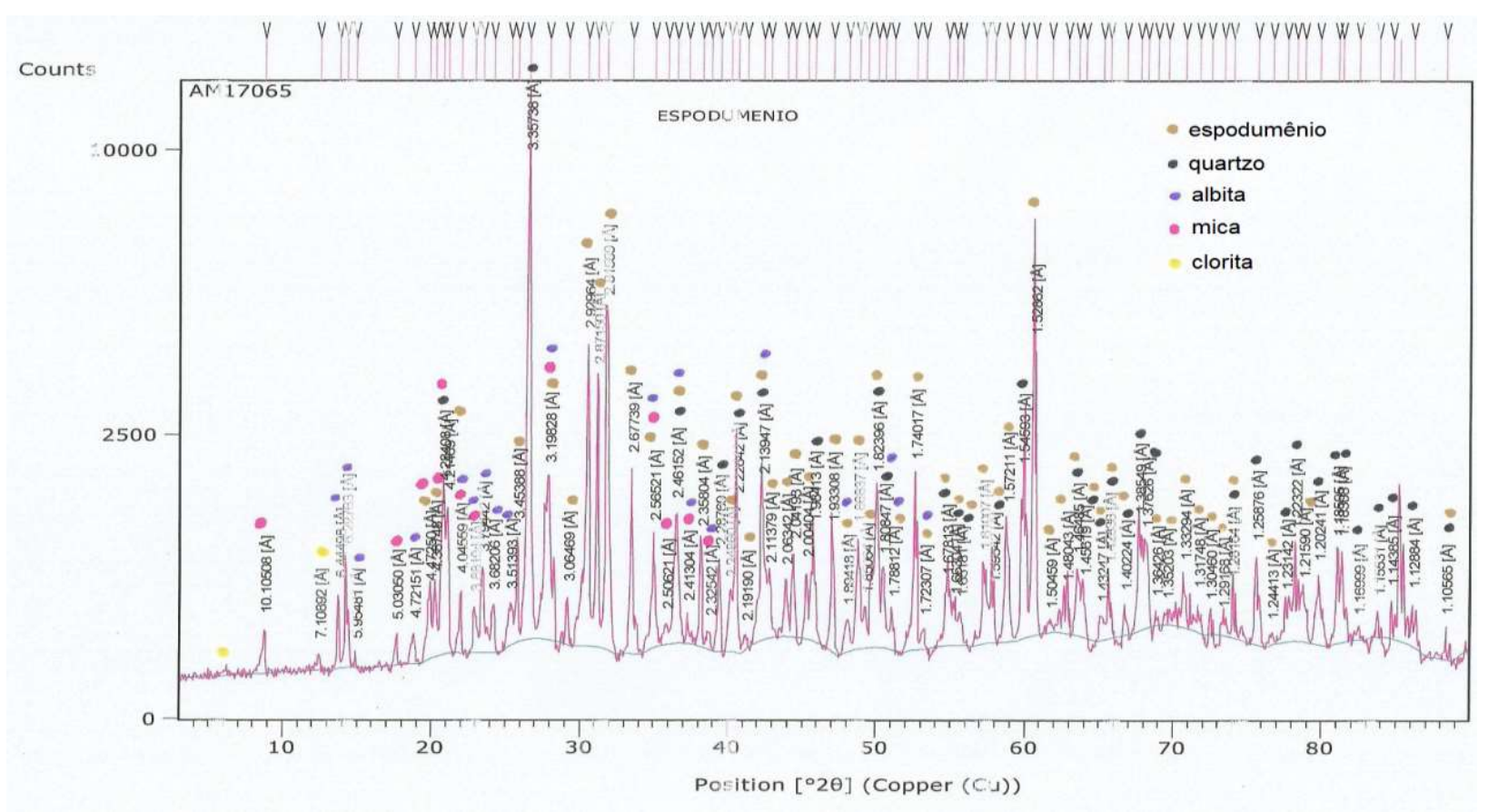

Fonte: Pesquisa aplicada, 2017.

Através do difratograma foi possível identificar as principais fases minerais presentes na amostra do pegmatito, sendo estes o espodumênio, o quartzo, a albita, a mica e a clorita. Como esperado, tais minerais são os mais encontrados em pegmatitos litiníferos provenientes da região estudada, no caso o nordeste de Minas Gerais (ROMEIRO e SOARES, 2005).

No intuito de quantificar as fases minerais presentes, foi realizado o refinamento Rietveld para a mesma amostra. A figura 9 apresenta o difratograma obtido após o refinamento. 
Figura 9 - Refinamento Rietveld para a amostra de pegmatito

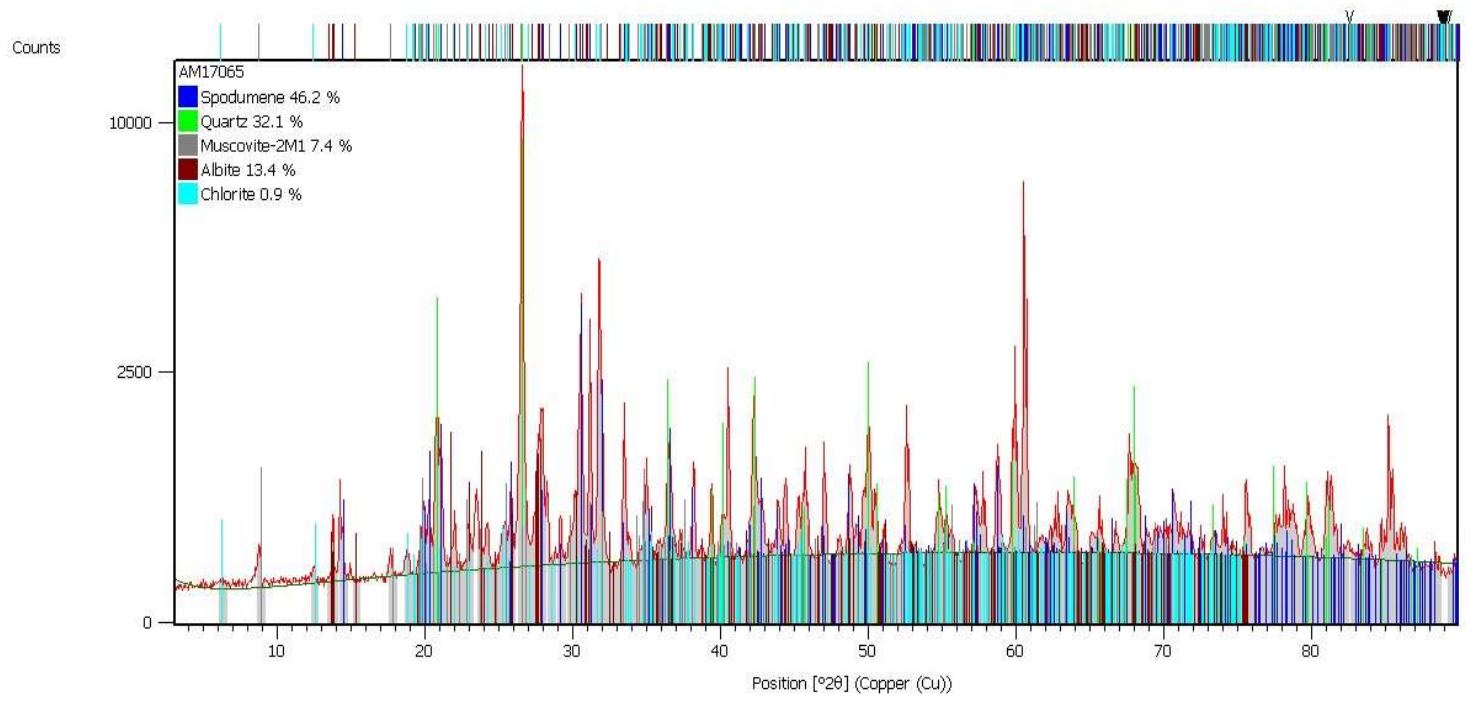

Fonte: Pesquisa aplicada, 2017.

A tabela 2 mostra os valores, em porcentagem, em massa das fases minerais presentes na amostra de pegmatitos obtidos pelo refinamento Rietveld.

Tabela 2 - Porcentagem em massa das fases cristalinas identificadas na amostra de pegmatito

\begin{tabular}{cccccc}
\hline \multirow{2}{*}{ Amostra } & Espodumênio & Quartzo & Albita & Mica & Clorita \\
\cline { 2 - 6 } & \multicolumn{5}{c}{$\%$} \\
\hline $\begin{array}{c}\text { Pegmatito } \\
\text { litinífero }\end{array}$ & 46,20 & 32,10 & 13,40 & 7,40 & 0,90 \\
\hline
\end{tabular}

Fonte: Pesquisa aplicada, 2017.

Como pode ser observado na tabela 2, o pegmatito litinífero apresentou alta porcentagem de espodumênio (46,20\%), principal mineral-minério que contém lítio. Tal fato evidencia o potencial dos pegmatitos da região de Araçuaí, visando o fornecimento de matéria-prima para a produção de compostos de lítio.

Os outros minerais encontrados, como quartzo, albita, mica e clorita, apresentaram-se como minerais de ganga dos minérios de espodumênio, uma vez que devem ser retirados na etapa de beneficiamento para a concentração de lítio. 


\section{CONCLUSÃO}

Os minerais litiníferos vêm ganhando grande destaque no setor mineral a nível mundial, especialmente por serem a principal fonte de lítio, considerado hoje como um metal estratégico devido a suas diversas aplicações em baterias, equipamentos portáteis e outros, gerando uma produção de energia limpa no futuro em carros elétricos.

A caracterização mineralógica é de extrema importância para se conhecer a rocha, subsidiando informações para o desenvolvimento de testes metalúrgicos mais adequados.

O pegmatito litinífero encontrado na região de Araçuaí apresentou bom desempenho físico, sem grandes gastos energéticos para adequação à caracterização. Com a avaliação mineralógica, foi possível observar que o espodumênio compreende $46,2 \%$ do total da amostra estudada, mostrando que o pegmatito possui potencial econômico para exploração de lítio.

\section{AGRADECIMENTOS}

Ao Departamento de Engenharia de Minas da UFMG pela contribuição na realização da análise mineralógica.

À UEMG e ao Programa Institucional de Apoio à Pesquisa, pela concessão da bolsa de iniciação científica durante a realização da pesquisa.

À Mina de Cachoeira, pertencente à Companhia Brasileira de Lítio, localizada em Araçuaí, região nordeste de Minas Gerais, pela doação de amostras de pegmatitos.

\section{REFERÊNCIAS}

ALMEIDA, A.B. de. Caracterização químico-mineralógica de minérios de manganês. . Dissertação de Mestrado. Universidade Federal de Minas Gerais, Escola de Engenharia Belo Horizonte, 2010, $87 \mathrm{f}$.

BRASIL. Associação Brasileira de Normas Técnicas: NBR NM 248 - Agregados Determinação da composição granulométrica, 2003.

BRAGA, P.F.A.; FRANÇA, S.C.A. Tecnologias para produção de carbonato e hidróxido de lítio a partir de espodumênio e ambligonita. In: Valorização de pegmatitos litiníferos. Eds.: Martins, L.M.P.; Oliveira, D.P.S. de; Silva, R.; Viegas, 
H.M.C; Villas Bôas, R.C. Lisboa, Portugal: DGEG/LNEG/ADI/CYTED, 2011, p. 5561. ISBN 978-989-675-016-9.

BRAGA, P.F.A.; SAMPAIO, J.A. Lítio. In: Rochas e Minerais Industriais no Brasil: usos e especificações. 2.ed. Rio de Janeiro: CETEM/MCTI, 2008, p. 585-603.

PORPHÍRIO, N.H.; BARBOSA, M.I.M.; BERTOLINO, L.C. Caracterização Mineralógica de Minérios: Parte I. 2010, p.57-84.Comunicação Técnica elaborada

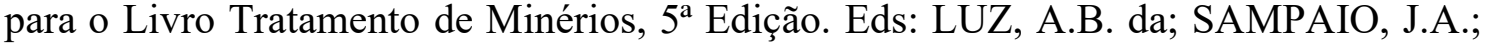
FRANÇA, S.C.A.

MARGARIDO, F.; VIECELI, N.; DURÃO, F.; GUIMARÃES, C; NOGUEIRA, C.A. Minero-metalurgical processes for lithium recovery from pegmatitic ores. Comunicações Geológicas, n.101, Especial II, p.795-798, 2014, ISSN: 0873-948X; eISSN: $1647-581 \mathrm{X}$

MATOS, H.L.S. Síntese de nanopartículas de óxido de ferro funcionalizadas para remoção de $\mathbf{P b}^{2+}$. Dissertação de Mestrado em Engenharia Química, Universidade Federal de Goiás, Goiânia-GO, 2016, 90f.

RODRIGUES, A.P.H. Estudo da adsorção de íon cádmio do meio aquoso utilizando compósito magnético Mn304/Fe304. Dissertação de Mestrado em Engenharia de Materiais, Centro Federal de Educação Tecnológica de Minas Gerais, Belo HorizonteMG, 2014, 130f.

ROMEIRO, J.C.P.; SOARES, A.C.P. Controle do minério de espodumênio em pegmatitos da mina de cachoeira, Araçuaí, Minas Gerais. Geonomos, vol.13.n 1 e 2, p. 75-81, 2005.

SAMPAIO, J.A.; SILVA, F.A.N.G.da. Análise Granulométrica por Peneiramento. In: Tratamento de Minérios: Práticas Laboratoriais. Eds.: SAMPAIO, J.A.; FRANÇA, S.C.A.; BRAGA, P.F.A. Rio de Janeiro: CETEM/MCTI, 2007. p.55-72.

VALADÃO, G.E.S.; ARAÚJO, A.C.de. Introdução ao tratamento de minérios. Belo Horizonte: Editora da UFMG, $1^{\text {a }}$ Ed., 234p. 2012.

YOUNG, R. A.; LARSON, A.C.; PAIVA-SANTOS, C.O. Rietveld analysis of x-ray and neutron powder diffraction patterns. Atlanta: School of Physics, Georgia Institute of Technology, 1998, 59p. 